\title{
Design and Development of Data Management System to Support The Preparation Process of Accreditation form for Program Study
}

\author{
Artin Finalita ${ }^{1}$ and Ervina Ahyudanari ${ }^{2}$ \\ ${ }^{1}$ Department of Technology Management, Institut Teknologi Sepuluh Nopember, Surabaya \\ ${ }^{2}$ Department of Civil Enginnering, Institut Teknologi Sepuluh Nopember, Surabaya \\ e-mail: setiawanartin@gmail.com
}

\begin{abstract}
In order to realize public accountability, the program study must actively build an internal quality assurance system. To prove that the internal quality assurance system has been implemented properly and correctly, the program study must be accredited by an external quality assurance institution. Criteria for evaluating commitments in accreditation are outlined in number of standards and are presented by programs study in instruments of forms. The problem that arises is that data/ documents for the process of supporting accreditation forms are not all available in the Program Study so they still have to involve other units to obtain them. The purpose of this study is to design a data management system to prepare the availability of data / documents to support the process of preparing accreditation forms. The System Development Life Cycle (SDLC) method is used with the waterfall model in designing this system. This research has produced an application system called Dokumen Akreditasi Online which is oriented towards standards of accreditation form. Overall the results of testing the system functionality shows that all features in the application can be run. The results of measuring the level of user satisfaction amounted to $75.27 \%$ which means that users are satisfied with this system. Thus, the need to prepare for accreditation is faster and easier and useful for other administrative needs.
\end{abstract}

Keywords-Accreditation, Borang, Data Manajemen; SDLC, Waterfall.

\section{INTRODUCTION}

A CCREDITATION is a quality assessment carried out by a team of peer experts (team of assessors) based on established quality standards, to obtain recognition that an institution or program study has met the specified quality standards, making it feasible to carry out its program [1]. Explanation of each standard in the framework of accreditation is presented by the study program in the form of instruments, which are a collection of data and information about inputs, processes, results, and impacts characterized by efforts to improve the quality of performance. During this time the documents used to compile the forms are still fragmented and there are still some that are stored manually (not yet stored in one container). The officer must look for documents in a pile of files so it requires quite a long time. It is necessary to build a system to facilitate the management of supporting documents needed Especially during the visitation process the document accreditation in the form of hardcopy becomes evidence to be shown to the assessor. The purpose of this study is to discuss project activities in building a data center information system application that is able to provide facilities for meeting data needs in Program Study. Documents will be managed and documented based on existing accreditation standards. With this system the preparation of data availability especially in the process of filling accreditation forms become faster and easier and also be utilized to assist in managing and maintaining all documents produced from all organizational, administrative and academic activities.

\section{A. Problem}

This study purpose to design and develop an information system oriented to the standards of accreditation BAN-PT to provide convenience the data needs in the Program Study for the process of preparing accreditation forms.

\section{B. Scope of Problem}

The scope of problem in this research are:(1)This research was conducted in the ITS Computer Engineering Study Program in the framework of preparing the BAN-PT Study Program Accreditation process; (2)The preparation of the study follows the BAN-PT 2018 accreditation format; (3)Using the System Development Life Cycle (SDLC) method with the waterfall model with the stages of identifying the needs, design, implementation and testing of the system.

\section{Purpose}

The purpose of this study to discuss activities in building a data center information system application that is able to provide facilities for meeting data needs in Program Study. Documents will be managed and documented based on existing accreditation standards. With this system the preparation of data availability especially in the process of filling accreditation forms become faster and easier and also be utilized to assist in managing and maintaining all documents produced from all organizational, administrative and academic activities.

\section{Benefit}

This researh have banefit: (1)Help managing and maintaining all documents produced from all organizational, administrative and academic activities; (2)Documents are more accessible for various purposes and document security in terms of physical damage can be avoided; (3)Understanding the use of the SLDC Method with the waterfall concept in designing a system. Add affiliation 
The $1^{\text {st }}$ International Conference on Business and Engineering Management (IConBEM 2020)

February $1^{\text {st }} 2020$, Institut Teknologi Sepuluh Nopember, Surabaya, Indonesia

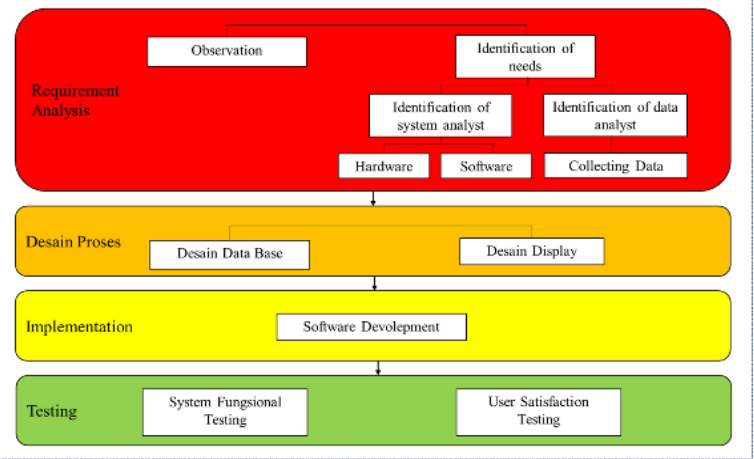

Figure 1. The research systematics use SDLC method.

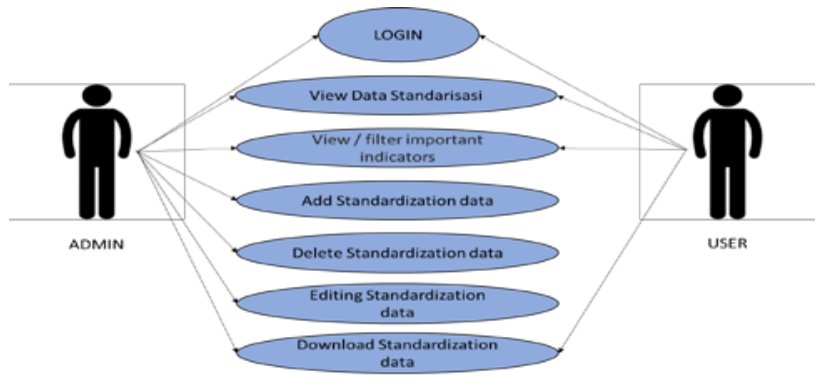

Figure 2. Use Case Diagram.

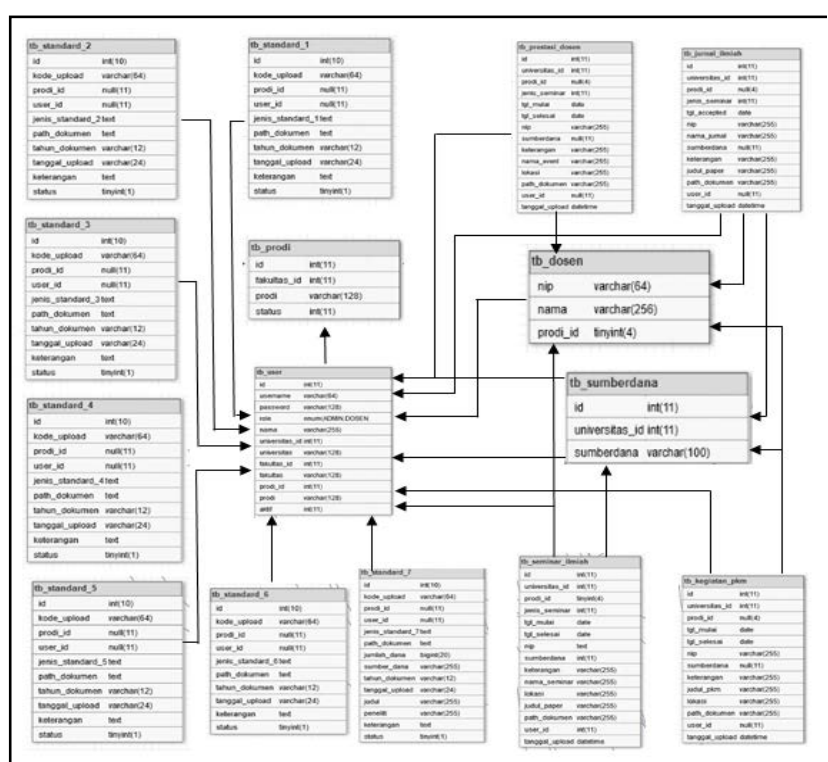

Figure 3. Database Design.

description for all authors and the affiliations are cited by superscripts as shown in the above example. Add an asterisk $(*)$ in superscript to the corresponding author.

\section{METHOD}

The research systematics used is the System Development Life Cycle (SDLC) with the waterfall model. This method used 4 stages namely requirements analysis, desain proses, implementation and testing in Figure 1.

\section{III.RESULT AND DISCUSSIONS}

This section will discuss research activities to build a data management system application with a focus on activities for the preparation of study program accreditation.

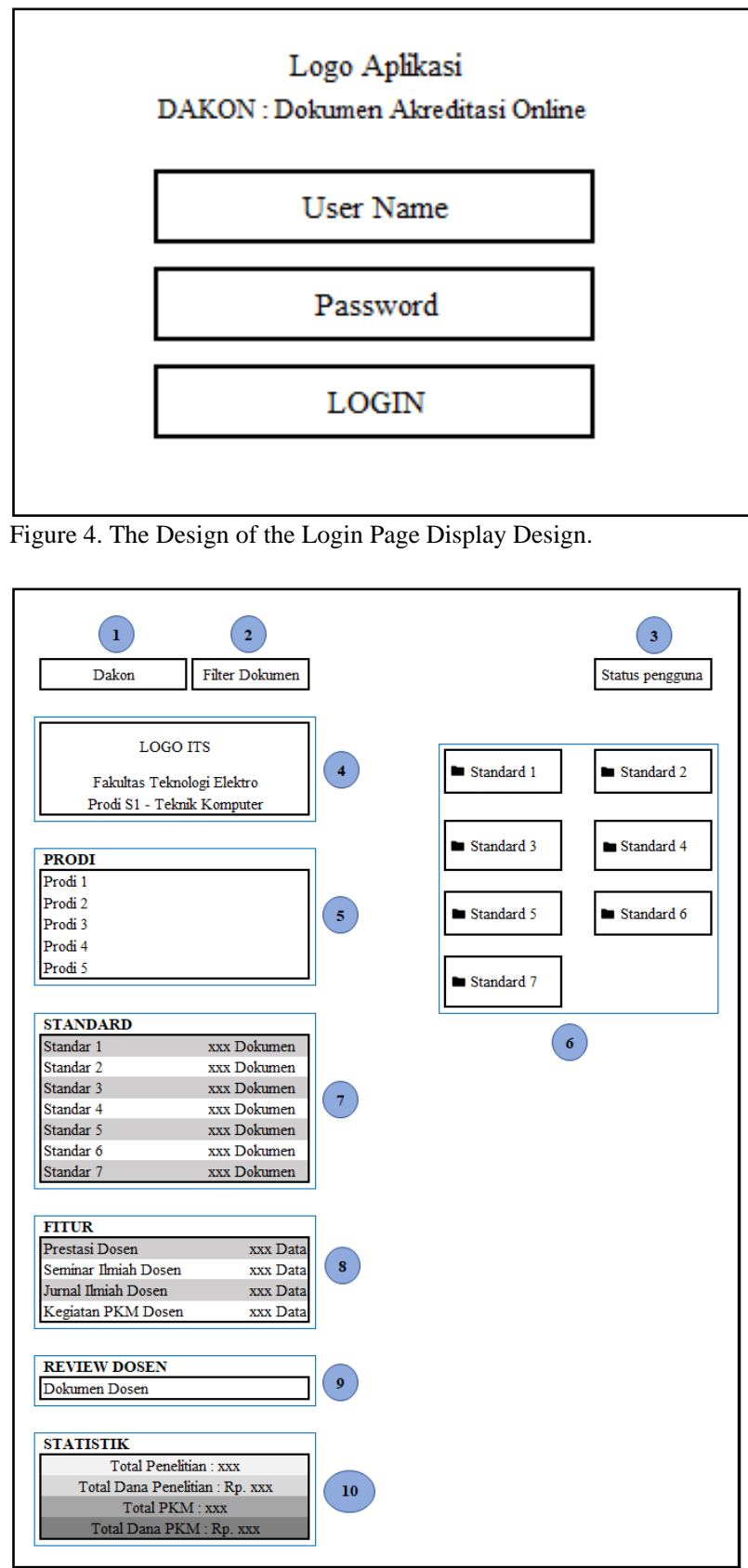

Figure 5. Main Page Display Design.

\section{A. Requirement Analyst}

Figure 2. illustrates the use case diagram for user management to be developed. Use case diagram is a diagram used to illustrate the application functionality of users who use the application. While the results of the operational needs of the system which includes hardware requirements (hardware) and software (software) are as follows: Server Specifications: (a)Using a server with Linux open source operating system (preferred); (b)Installed web server and mysqli server; (c)Have a minimum of 4GB RAM; (d)Have a minimum 50 GB hard drive; (e) Connected at a minimum LAN Client Specifications: (a)Using a minimum 32-bit Operating System (Windows, Linux); (b)Have a minimum of 4GB RAM; (c)Have a minimum of 50 GB hard drive (d)A computer / laptop must be connected to a LAN at a minimu 
The $1^{\text {st }}$ International Conference on Business and Engineering Management (IConBEM 2020)

February $1^{\text {st }} 2020$, Institut Teknologi Sepuluh Nopember, Surabaya, Indonesia

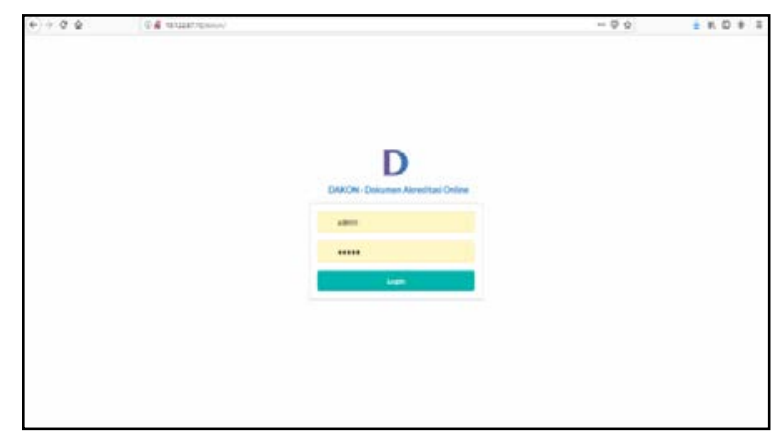

Figure 6. Login Page Display.

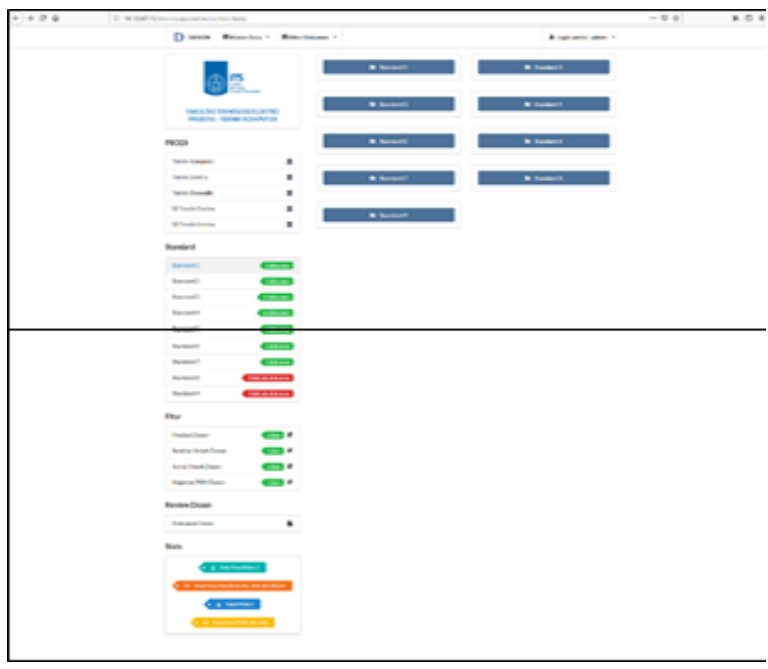

Figure 7. Main Page Display.

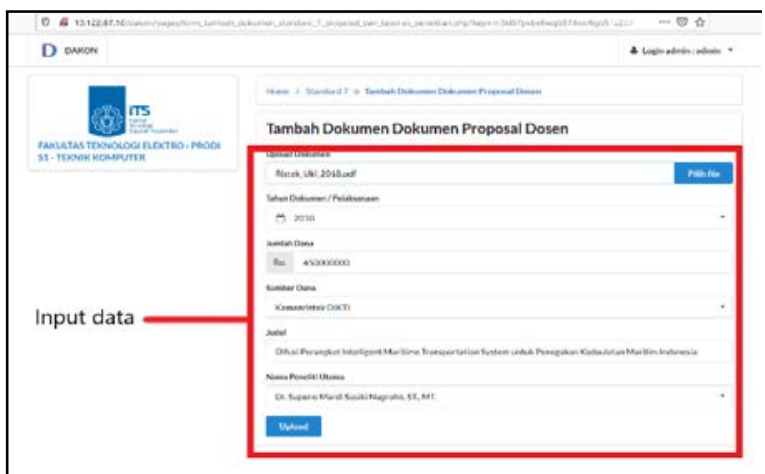

Figure 8. Test case input data.

Data and document identification are carried out to answer the questions in each accreditation standard. The identification process is adjusted to III-A Book of Accreditation Forms and then the data collection process is carried out.

\section{B. Desain Proses}

Next will be discussed regarding the design (design) which includes the design of database systems, design or display design.

\section{1) Database Design}

The next step is database design which is used to explain the relationship between data in the system. Figure 3. Figure 3 is the result of database design where a table in the database represents a data entity.The data table design is used to provide information about what data is needed in
Table 1.

Functional Testing of Information System

\begin{tabular}{clr}
\hline \hline No & Testing & $\begin{array}{c}\text { Mozilla } \\
\text { Firefox }\end{array}$ \\
\hline 1 & Display in Web Browser & \\
2 & System login & \\
3 & Operating the system as an admin & $\checkmark$ \\
4 & Operating the system as a user & $\checkmark$ \\
5 & Data save operation & \\
6 & Data edit operation & $\checkmark$ \\
7 & Operation appears data & $\square$ \\
8 & Erase data operation & $\square$ \\
9 & File upload operation & $\square$ \\
10 & File upload operation & $\square$ \\
11 & Operation of document filters & $\square$ \\
12 & System logout & $\square$ \\
\hline \hline
\end{tabular}

Table 2.

Aspects of Consumer Satisfaction

\begin{tabular}{|c|c|}
\hline Code & Question \\
\hline A & $\begin{array}{l}\text { Do you agree that the appearance of the Information } \\
\text { Systems Visitation Accreditation for Informatics } \\
\text { Engineering Study Program is attractive and easily } \\
\text { accessible? }\end{array}$ \\
\hline B & $\begin{array}{l}\text { Do you agree that the features provided in the } \\
\text { Information Engineering Accreditation Information } \\
\text { System Study Program are complete? }\end{array}$ \\
\hline $\mathrm{C}$ & $\begin{array}{l}\text { Do you agree that the Information Systems } \\
\text { Accreditation Information System Study Program of } \\
\text { Informatics Engineering has fulfilled the needs of } \\
\text { users? }\end{array}$ \\
\hline D & $\begin{array}{l}\text { Do you agree that the response time given by the } \\
\text { Information Engineering Accreditation Information } \\
\text { System Study Program is fast enough? }\end{array}$ \\
\hline E & $\begin{array}{l}\text { Do you agree that the menus on the Information } \\
\text { Systems Accreditation Information System Study } \\
\text { Program in Informatics have been going well? }\end{array}$ \\
\hline
\end{tabular}

development information systems. (1) User Table: The user table is used to store administrator data. in this table there are user username and password data which can only be known by the user himself. In the user system is distinguished by its type, namely as a user and as an admin; (2)Prodi Table: This table is used to store data on the names of program study in the Faculty; (3)Standard tables: are used to store accreditation forms data in accordance with their respective standards. The data in the database table for standards 1 to 6 are the same. While the data in the table for standard 7 there is little difference where there are additions related to the amount and source of funding for lecturer activities; (4)The lecturer table: is used to store lecturer data with the main components being the name of the lecturer, lecturer NIP and homebase of each lecturer; (5)The scientific seminar table: is used to store data on lecturer seminar activities with components including the type of seminar, date of implementation, seminar name, location and source of funds; (6)The lecturer achievement table: is used to store the achievement data held by the lecturer. Like the scientific seminar table on the lecturer achievement table, add the event activity name; (7)The PKM lecturer activities table: is used to store data of community service activities conducted by the lecturer. The main components of data stored are the date of implementation, location of activities, title of activities and 
The $1^{\text {st }}$ International Conference on Business and Engineering Management (IConBEM 2020)

February $1^{\text {st }} 2020$, Institut Teknologi Sepuluh Nopember, Surabaya, Indonesia

Table 3.

Aspects of Consumer Satisfaction

\begin{tabular}{ll}
\hline \hline Indicator & Value \\
\hline Disagree & 1 \\
Less Agree & 2 \\
Quite Agree & 3 \\
Agree & 4 \\
Disagree & 5 \\
\hline \hline
\end{tabular}

Table 4.

Aspects of Consumer Satisfaction

\begin{tabular}{ll}
\hline \hline Percentage & Information \\
\hline $81 \%-100 \%$ & Very Satisfied \\
$61 \%-80 \%$ & Satisfied \\
$41 \%-60 \%$ & Quite Satified \\
$21 \%-40 \%$ & Less Satisfied \\
$0 \%-20 \%$ & Not Satisfied \\
\hline \hline
\end{tabular}

sources of funds; (8)Scientific journal tables: are used to store data related to journals / papers written by lecturers with the main components being the date of receipt of the paper and the title of the paper published; (9)The scientific journals table: is used to store the data units providing funding used for various lecturer activities, both seminar, research and PKM.

\section{2) Disply Design}

The display design serves as a reference to create a user interface in system implementation. This design includes the design of the user login page and the design of the main page as shown in "Figure 4. and "Figure 5. (1)Dakon menu is the main page display menu. On the main page there are other menus whose functions are to carry out processes such as creating, reading, updating, deleting and downloading documents; (2)The Filter Menu is designed to facilitate the process of finding data quickly and precisely; (3)User Status, the section that displays whether the user is an admin or the user is only a user; (4)Identity Contains the ITS logo and shows the name of the Faculty and the name of the Study Program. For the name of the Faculty and Study Program this view will change according to the choices on the Study Program menu; (5)Menu Prodi, displays the choice of study programs in the Faculty because this application is also prepared for the needs of accreditation for all study programs within the Faculty; (6)Menu Standard, contains the. Standard 1 to Standard 7 menus. When the user wants to enter the data entry process and upload a document, he must first choose a standard then proceed with selecting the standard document type. The type of standard document used is a list of standard documents resulting from the identification of data requirements for accreditation. Thus the uploaded documents have a place in accordance with their respective standards; (7)Standard Display is a menu that is ready to display the results of the number of documents that have been loaded and stored on each standard. Here the user can also view the document and perform download or delete documents if desired; (8)Feature Menu is intended to display lecturer data from Tridarma activities that have been carried out such as lecturer achievements, scientific seminars, scientific journals and PKM activities. The amount of data entered will be captured and appear on the main page in the features section; (9)Lecturer Review, to see in detail the documents of each lecturer from all standards based on the results of data that has been inputted; (10)Stat Display Menu is a feature to view the results of statistical data on the amount of research activities and community service and the total amount of research funds, which are used from both activities.

\section{Implementation}

The implementation of the system is the stage of implementing the design that has been done. The result of this application system design is called the Dokumen Akreditasi Online (DAKON). This application system is also prepared for the needs of accreditation for all study programs that are within the scope of the Faculty, but currently the limitation of the use of applications is still in the Computer Engineering study program. At this stage, the design that has been created is implemented using number of applications and programming as follows: (1)Notepad ++ which functions as a text editor; (2)PHP which functions to make the website display dynamic and interactive; (3)Mysqli which functions as a data storage or database server.Figure 6 displays the login page, while Figure 7 displays the main page. On the initial appearance of the login page, the user must fill in their username and password to enter the system where each user has different access rights.

\section{Testing}

System testing is a process to ensure the success of the system created. Testing the information system of this Online Accreditation Document is done in two ways, namely functional testing and testing the level of user satisfaction using a questionnaire.

\section{1) System Functional Testing}

To carry out functional testing of this system is done by doing a test case as follows, for example: Activity : inputing lecturer research data on standard 7. Steps: (1)Enter the application system by logging in; (2)Choose standard 7, choose add standard document 7 and choose lecturer proposal document; (3)Perform data input and upload documents, as follows Figure 8. System testing is carried out to ensure the success of the system that has been created. Overall the results of testing the system functionality obtained as shown in Table 1. From table 1, it can be concluded that all functional aspects of the Online Accreditation Document information system computer engineering study program are functioning properly.

\section{2) User Satisfication Testing}

User satisfaction testing is a stage to measure the level of user satisfaction with the Online Accreditation Document information system. This test is carried out by the admin, the managemen of study program, the accreditation team, the admin staff as well as the lecturers involved in the study program accreditation process with 11 respondents. In the testing process, respondents gave an assessment of 5 questions. Rating given is based on the assessment indicators as in Table 3. Meanwhile, to find out the level of user satisfaction, used indicators of user satisfaction shown in Table 4 . The total value of the maximum rating indicator $=$ 275 . Percentage of user satisfaction (\%) 
The $1^{\text {st }}$ International Conference on Business and Engineering Management (IConBEM 2020)

February $1^{\text {st }} 2020$, Institut Teknologi Sepuluh Nopember, Surabaya, Indonesia

$$
\begin{aligned}
& =\frac{\text { Total user Value }}{\text { Total Max Volume }} \\
& =\frac{207}{275} \times 100 \% \\
& =75,27 \%
\end{aligned}
$$

Based on the measurement results of the level of user satisfaction, it can be concluded that the user is satisfied with the information system of the Online Accreditation Document for Computer Engineering Study Programs with a percentage of satisfaction of $75.27 \%$ which is included in the range $(61 \%-80 \%)$.

\section{IV.CONCLUTION}

Development of an Dokumen Akreditasi Online (DAKON) information system that adopts the SDLC method with the waterfall model, for 4 stages, namely requirements analysis, design, implementation, and testing, this web-based has can be run on localhost with a web browser (Mozilla Firefox). Through testing, it is known that all features have been able to function in accordance with the expected needs.The results of testing to 11 respondents to measure the level of user satisfaction on questions answered, the results obtained a percentage of $75.27 \%$ which means that users are satisfied with this system. This website-based information system can assist in the provision of data and document storage needed in the process of compiling the accreditation forms of study program so as to provide effectiveness and efficiency benefits

\section{V.RECOMMENDATION}

This information system has not provided new innovation features in the form of data analysis, for example, a recapitulation of values from internal assessors that can provide evaluations to study programs before being assessed by assessors from BAN-PT and dynamic standard data so that they can be adapted to new standard data when changes in rules accreditation forms assessment. At the next stage of development the version must be adjusted to the new accreditation instrument with 9 criteria of accreditation standards from BAN PT. For management, the accreditation forms application is intended to be used as an evaluation material, so that the study program can make performance improvements to optimize education quality standards in the study program.

\section{REFERENCES}

[1] PT. BAN, Buku I Naskah Akademik Akreditasi Program Studi Sarjana. Jakarta: BAN-PT, 2008. 